\title{
Arc Motion and Gas Flow in Current Limiting Circuit Breakers Operating With a Low Contact Switching Velocity
}

\author{
John W. McBride, Kesorn Pechrach, Member, IEEE, and Paul M. Weaver
}

\begin{abstract}
Arc motion in low voltage (240 VAC) high current $\left(10^{3}-10^{4} \mathrm{~A}\right.$.) current limiting-circuit breakers is dominated by arc root mobility. The mobility is influenced by the gas flow and gas composition in the contact region, but there is little experimental data on these effects. New pressure and spectral data measurement during arc movement are presented using a flexible test apparatus and an arc imaging system. These measurements are used to investigate gas flow characteristics in the arc chamber. The chemical and physical phenomena occurring during the arc motion are discussed. The combination of optical and spectral data provides new insight into the arc motion. The influences of arc chamber material, contact material, and contact opening speed, are investigated, to improve arc control for a low contact opening velocity.
\end{abstract}

Index Terms-Arc chamber material, arc imaging system, arc motion, arc root mobility, contact opening speed, current limitingcircuit breaker, flexible test apparatus, gas flow, velocity.

\section{INTRODUCTION}

$\mathbf{M}$ INIATURE circuit breakers (MCBs) are widely used to protect electrical facilities within commercial, domestic and light industrial buildings. The circuit breakers considered here are current limiting devices commonly used with supply voltages in the range $220-250 \mathrm{~V}$ ac and rated currents in the range $1-100 \mathrm{~A}$.

These devices protect against short circuit faults of $10^{3}-10^{4}$ A. During the short circuit fault an electric arc is drawn between opening contacts. In circuit breakers of current limiting design, the current through the conductors of the $\mathrm{MCB}$ generates a magnetic field in the arc chamber. This forces the arc away from the contact region along arc runners and into an arc stack where the arc is split into a number of series arcs. This results in a high arc voltage which counteracts the supply voltage to limit the peak fault current. The energy released by the fault is reduced and damage to both the circuit and the circuit breaker is minimized.

In commercial circuit breakers the performance is dependent on rapid opening of the contacts, typically a solenoid hammer action is used to produce an opening velocity above $6 \mathrm{~m} / \mathrm{s}$. This

Manuscript received September 12, 2001; revised November 1, 2001. This paper was presented at the IEEE Holm Conference, Montreal, QC, Canada, September 10-12,2001. This work was recommended for publication by Guest Editor J. W. McBride upon evaluation of the reviewers' comments. This work was supported byEPSRC and Chugai (USA).

J. W. McBride and K. Pechrach are with the School of Engineering Science, Electro-Mechanical Research Group, University of Southampton, Southampton S017 1BJ, U.K

P. M. Weaver is with the PBT, Ltd., Harlow, Essex, U.K.

Digital Object Identifier 10.1109/TCAPT.2002.804607 has been shown as a key factor in arc mobility, reducing the time taken for the arc to move into splitter plates. This velocity requirement leads to a complex mechanical design of the contact switching mechanism. Effective current limitation at reduced contact velocity would permit the construction of less complex, more reliable, mechanisms employing advanced active materials actuation. In order to achieve this, a better understanding of the magnetic, gas dynamic and chemical effects on arc mobility during contact opening is required. The aim of the research presented here is to investigate the arc motion at a low velocity of $1 \mathrm{~m} / \mathrm{s}$ using a highly developed measurement system. The low velocity of $1 \mathrm{~m} / \mathrm{s}$ is more typical of switching devices rather than circuit protection devices.

Recent studies [1]-[5] have shown that the venting of the arc chamber has a major influence on the arc root motion. In [1] the gas flow around the moving contact and gas venting from the arc chamber was shown to have an important influence on the commutation of the arc root from the moving contact to the arc runner. This was particularly evident with the anode arc root on the moving contact. In these studies the so call "immobility" period at the beginning of the arcing process was shown to be caused by a complex interaction of physical processes [2].

Previous investigations [6]-[8] of pressure effects on arc motion indicate that the period of arc immobility in the contact region coincided with a period of constant pressure. It has been identified that the pressure in the arc chamber is dependent on the cross-sectional area. A wider chamber reduced the immobility time. The composition of the arc chamber gases affects circuit breaker performance primarily by its effect on dielectric properties within the arc chamber [9], [10]. This could be caused by increased gas flow from ablating materials resulting in a faster deionization of the plasma [7]. The effects of gas composition on arc mobility are less well understood.

The objective of this paper is to present data on the gas flow and gas composition effects in the contact region, and to investigate these effects in systems operating with reduced contact opening velocity. The two main applications for this experimental study are for the verification of computer models and in the development of a new device. The optical fiber arc imaging system described previously [1], [3] was used for this paper to obtain detailed new data on the arc root motion. The system monitors arc motion at 1,000,000 images/s. Computational manipulation of the optical data permits the identification of parameters describing the motion of both cathode and anode arc roots on fixed and moving contacts. Simultaneously, novel data on the gas composition and flow characteristics were obtained 
by means of piezo resistive differential pressure transducers and optical fiber spectrometer techniques. These instrumental techniques were used to study the influence of arc chamber material, contact material and contact opening speed on arc root mobility during contact opening. The arc chamber parameters were varied using a flexible test apparatus described previously [5]. Novel results are presented on the effects of gas flow and composition on arc root mobility during contact opening for contact opening velocities of $10 \mathrm{~m} / \mathrm{s}$ and $1 \mathrm{~m} / \mathrm{s}$.

\section{EXPERIMENTAL METHODS}

\section{A. Arc Imaging System}

The arc imaging system used to record the motion of the arc has been described previously [1], [3]. In summary, optical fibers transmit light from the arc chamber to an array of detectors and data acquisition. Data analysis is based on selected fibers as described previously [1], [3]. Using the system, clearly defined parameters are used to measure the arc motion performance. The two main parameter used are the fixed contact time and the moving contact time. In the experiments presented here the anode is always on the moving contact, leading to the "anode root time" on the moving contact and the "cathode root time" on the fixed contact. The arc root contact time on the moving contact is defined as the time difference between the start of the arc and the point that the root passes $10 \mathrm{~mm}$ displacement. This corresponds to the point at which the arc commutates from the moving contact to the arc runner. The arc root contact time on the fixed contact is defined as the time between the start of the arc and the time at which the arc root moved away from the region.

\section{B. Flexible Test Apparatus}

The flexible test apparatus incorporating the arc imaging system and other instrumentation is shown schematically in Figs. 1-3. The system is described in detail elsewhere [1]-[4]. The circles over the arc chamber indicate the positions of the optical fibers. The contacts are opened with a solenoid mechanism. The short circuit current was generated by capacitor discharge. The positions and geometries of the arc stack, arc runners, arc chamber materials, arc chamber venting and contact opening velocity can be varied to provide a flexible arc chamber configuration allowing a systematic variation of the parameters. The system has been modified by the inclusion of pressure measurement instrumentation and access for an optical fiber spectrometer as described below.

\section{Pressure Measurement}

The gas pressure in the arc chamber is monitored using two piezo-resistive differential pressure transducers. The pressure transducers are calibrated against a gauge pressure standard. Locations of pressure transducers are shown in Figs. 2 and 3, but in any experiment only two locations are used, either behind the arc stack and behind the moving contact, or behind the arc stack and between the opening contacts.

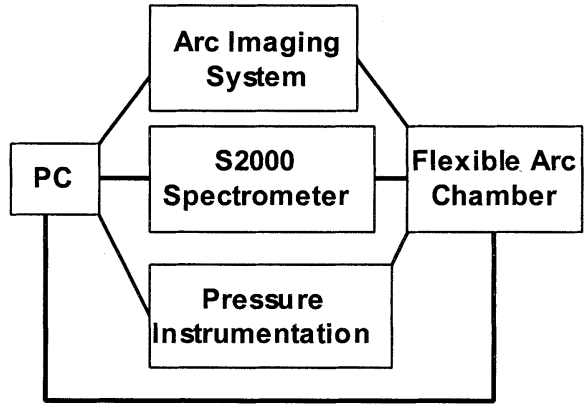

Fig. 1. Schematic diagram of the experimental cofiguration.

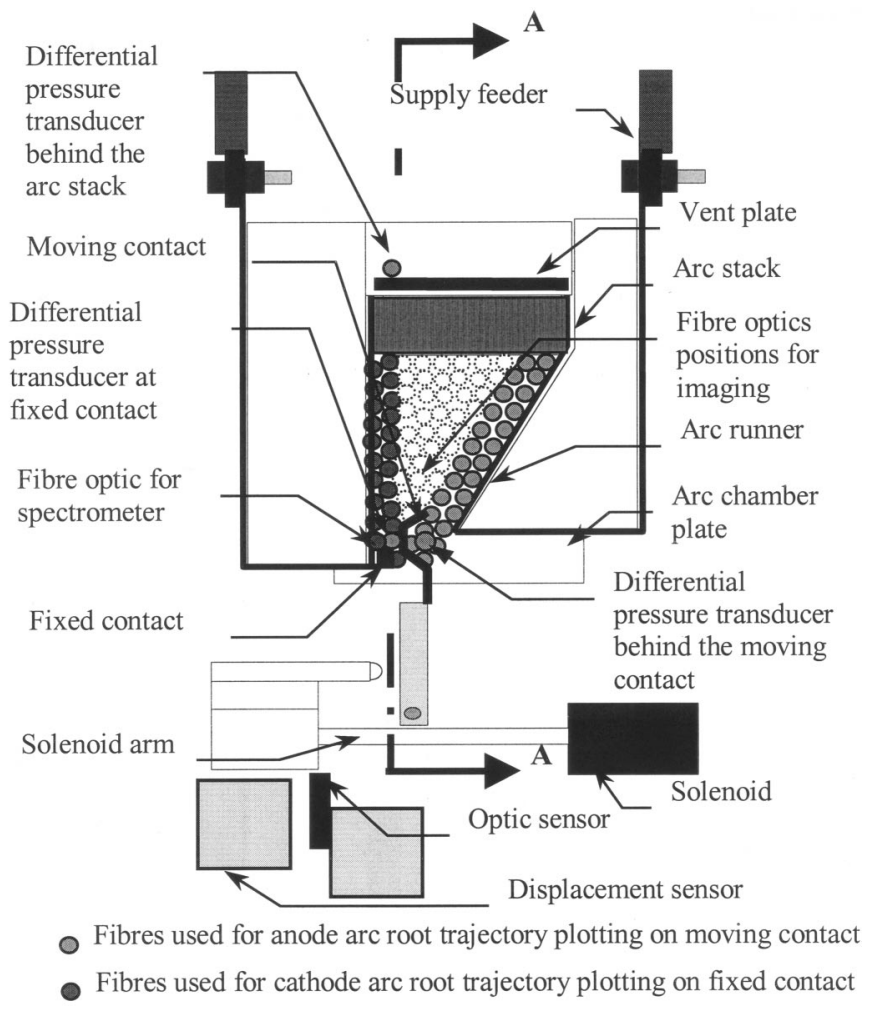

Fig. 2. Arc chamber configuration in the flexible test apparatus (FTA).

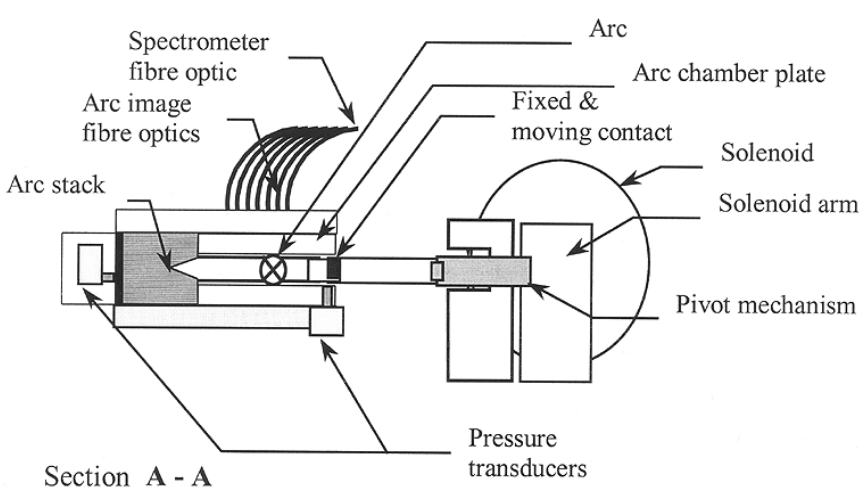

Fig. 3. Cross section (seen from A-A in Fig. 2) of the flexible test apparatus (FTA).

\section{Spectrometer Measurement}

A PC based optical fiber spectrometer [11] is used to monitor the gas composition in the arc chamber. The spectrometer accepts light energy transmitted through an optical fiber and dis- 
TABLE I

CONSTANT Factors VALUe FOR All EXPERIMENTS. THE CONTACT FORCE IS INDEPENDENT OF THE OPENING VELOCITY

\begin{tabular}{l|l}
\hline \hline Constant factors & Value \\
\hline \hline Voltage level (dc charge) & 340 Volts \\
\hline Inductance & $224 \mu \mathrm{H}$ \\
\hline Capacitance & $47.4 \mathrm{mF}$ \\
\hline Final contact gap & $6 \mathrm{~mm}$ \\
\hline Contact mechanism & Pivoting mechanism \\
\hline Peak short circuit current & $2000 \mathrm{~A}$. \\
\hline Moving contact & Silver plated copper \\
\hline Contact polarity & Anode on moving contact, \\
& Cathode on fixed contact \\
\hline Contact opening delay $\mathrm{t}_{\mathrm{cod}}$ & $500 \mu \mathrm{s}$ \\
\hline Chamber depth & $6 \mathrm{~mm}$ \\
\hline Chamber attitude & Horizontal \\
\hline Arc stack displacement & $35 \mathrm{~mm}$ \\
\hline \hline
\end{tabular}

perses it via a fixed grating across a CCD array detector. The CCD detector uses 2048 linear elements, with an effective range from 200-1100 nm. The spectrometer measures the amount of light and the $\mathrm{A} / \mathrm{D}$ converter transforms the analog data into digital information. The integration time is software controlled between $3 \mathrm{~ms}$ and $6 \mathrm{~s}$. For the purposes of the experimental procedure used here the integration time is set at $1 \mathrm{~s}$. The system is triggered at the start of the arcing process and collects the light from the arc while the arc is in the contact region.

\section{E. Experimental Methods}

There are four main variable parameters investigated in this paper.

1) Contact velocity:- $10 \mathrm{~m} / \mathrm{s}$ and $1 \mathrm{~m} / \mathrm{s}$.

2) Contact materials: $\mathrm{Ag} / \mathrm{C}$ (5\% Graphite)

Ag/C flat: Silver/Graphite contact pad flush without a step to the surface of the arc runner.

Ag/C step: Silver/Graphite contact pad with a step to the surface of the arc runner.

Cu punch: Plain copper runner with a punch to give a definite area of arc ignition.

3) Arc chamber materials:

\section{-Ceramic.}

\section{-Polycarbonate:}

$\left[-\mathrm{O}-\left(\mathrm{C}_{6} \mathrm{H}_{5}\right)-\mathrm{C}\left(\mathrm{CH}_{3}\right)_{2}-\left(\mathrm{C}_{6} \mathrm{H}_{5}\right)-\mathrm{OCO}_{2}-\right] n$.

4) Arc chamber venting-Opened: vent area $100 \%$ $\left(42 \mathrm{~mm}^{2}\right)$. Choked: vent area $15 \%$. Closed: vent area $0 \%$.

During all the experiments the parameters listed in Table I were kept constant. Further details of the experimental procedure and constants can be obtained in [1], [3], [4]. To investigate the influence of a reduced contact velocity on the arc motion performance the following investigations have been undertaken. For each experimental condition between one and two sets of contacts and arc runners are used, this has been shown previously to allow between 20 and 40 experiments to be undertaken for each set. Initial tests are undertaken to allow preconditioning of the materials before data is collected.

- Experiment A. The gas flow in the contact region is investigated to show the relationship between gas pressure and arc motion.

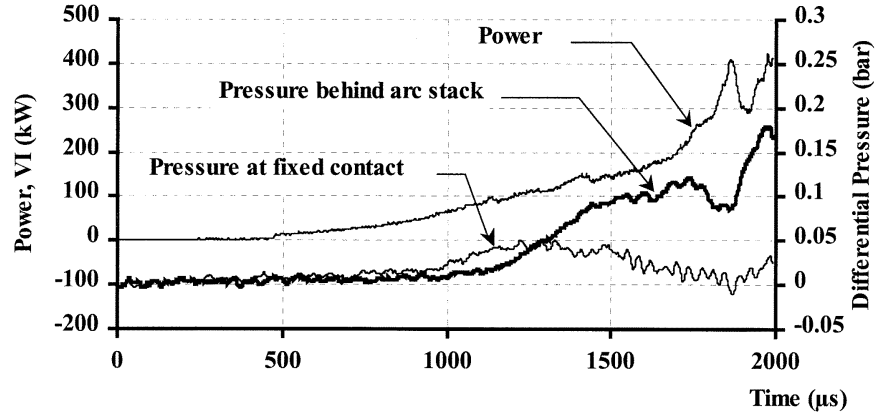

Fig. 4. Pressure in the fixed contact region on $\mathrm{Ag} / \mathrm{C}$ flat contact material, Contact velocity $10 \mathrm{~m} / \mathrm{s}$, Choked arc chamber venting condition, Polycarbonate arc chamber, anode on moving contact and cathode on fix contact.

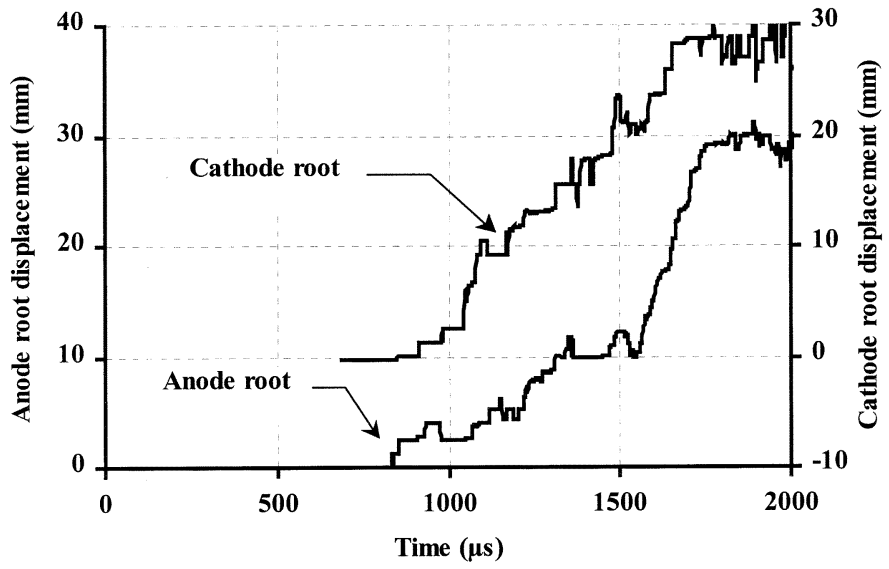

Fig. 5. Anode and cathode root displacement corresponding to Fig. 4, with $\mathrm{Ag} / \mathrm{C}$ flat contact material, Contact velocity $10 \mathrm{~m} / \mathrm{s}$, Choked arc chamber venting condition, Polycarbonate arc chamber, anode on moving contact and cathode on fix contact.

- Experiment B. To demonstrate the influence of gas flow around the moving contact on arc commutation.

- Experiment C. To investigate the influence of contact velocity.

- Experiment D. To investigate the role of the side wall material on arc commutation at low contact velocity.

\section{RESULTS AND DISCUSSION}

\section{A. Experiment A: Gas Flow in the Contact Region}

In this study, the gas flow in the contact region is investigated under both high and low contact velocity configurations, the arc chamber is choked and a Polycarbonate wall material is used. In Fig. 4 at a contact opening velocity of $10 \mathrm{~m} / \mathrm{s}$, the pressure in the fixed contact region starts to rise when the cathode root has left the fixed contact region but the anode root has not moved off the moving contact as shown in Fig. 5. In Fig. 4 the pressure in the contact region and behind the arc stack is shown with the arc power. The pressure in the contact region is shown to peak at the same time as the anode arc root commutates to the arc runner, shown in Fig. 5 at the point where the anode root displacement passes $10 \mathrm{~mm}$. The maximum pressure at the fixed contact is approximately 0.05 bar. The pressure behind the arc stack rises with the arc power but drops after the first entry into the splitter plate as the arc moves backward before re-entering the plates. 


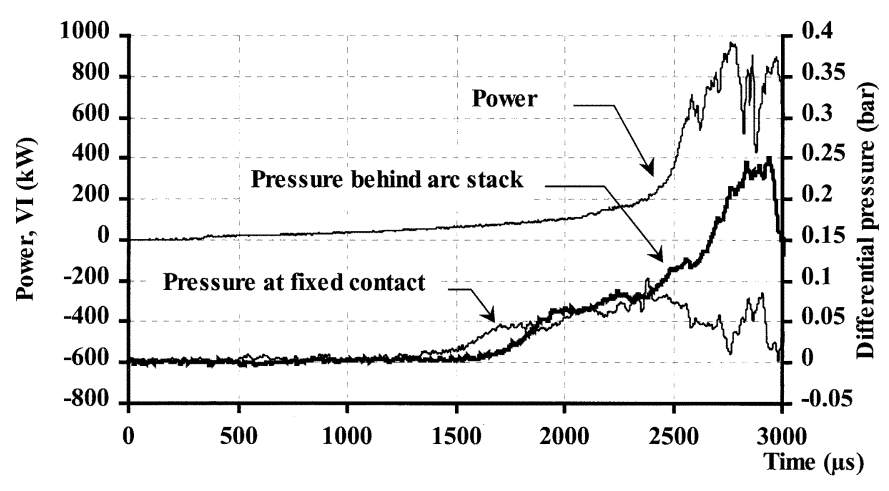

Fig. 6. Pressure in the fixed contact region on $\mathrm{Ag} / \mathrm{C}$ flat contact material, contact velocity $1 \mathrm{~m} / \mathrm{s}$, choked arc chamber venting condition, polycarbonate arc chamber, anode on moving contact, and cathode on fix contact.

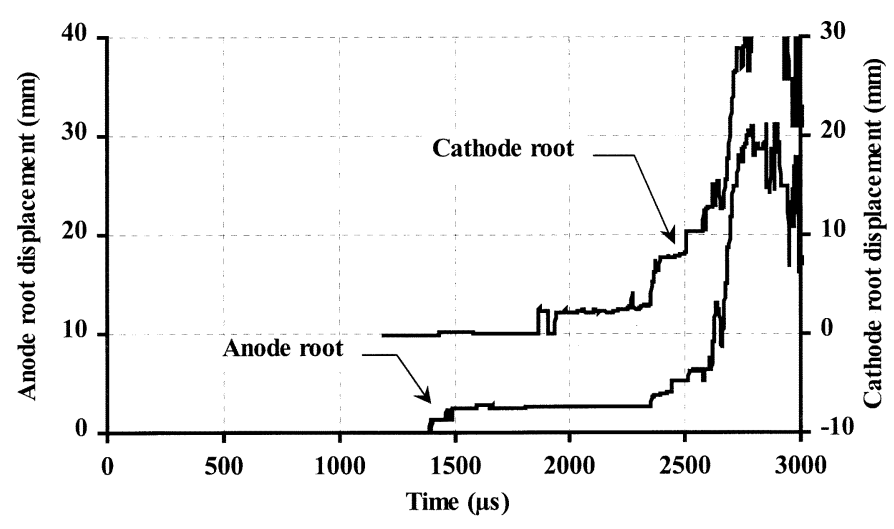

Fig. 7. Anode and cathode root displacement corresponding to Fig. 6, for a $\mathrm{Ag} / \mathrm{C}$ flat contact material, contact velocity $1 \mathrm{~m} / \mathrm{s}$, choked arc chamber venting condition, polycarbonate arc chamber, anode on moving contact, and cathode on fixed contact.

The results for a contact velocity of $1 \mathrm{~m} / \mathrm{s}$ are shown in Figs. 6 and 7 . The pressure at the fixed contact and behind the arc stack is shown with the arc power. The pressure starts to rise before either the anode or the cathode roots move from the contact region. In Fig. 7 the anode time as it passes the $10 \mathrm{~mm}$ level is shown to be $2700 \mu$ s from the start of the data. The maximum pressure at the fixed contact $(0.1 \mathrm{bar}$ at $2300 \mu \mathrm{s})$ occurs as the arc burns in the contact region. The pressure at a contact opening velocity of $1 \mathrm{~m} / \mathrm{s}$ starts to rise up later $(1400 \mu \mathrm{s})$ compared to the pressure at contact opening velocity $10 \mathrm{~m} / \mathrm{s}(600 \mu \mathrm{s})$. Also the peak pressure for $1 \mathrm{~m} / \mathrm{s}$ is double that for $10 \mathrm{~m} / \mathrm{s}$.

The high temperature gases lead to high pressure and increase the rate of formation of ionised species and electrons from the contact material. This results in increasing the electric field [9], column conductivity and magnetic field. However at $10 \mathrm{~m} / \mathrm{s}$ the arc moves away from the contact region faster than in the $1 \mathrm{~m} / \mathrm{s}$ case, and there is less time for pressure to build up. The integration of the arc power while the arc is in the contact region shows the arc energy dissipation to be $62 \mathrm{~J}$. At $1 \mathrm{~m} / \mathrm{s}$ both anode and cathode roots stay in the contact region for longer time. In this case the arc energy while the arc is in the contact region is $256 \mathrm{~J}$. This higher energy dissipation will produce more heat, higher temperature and higher pressure in the contact region, as shown in Fig. 6.

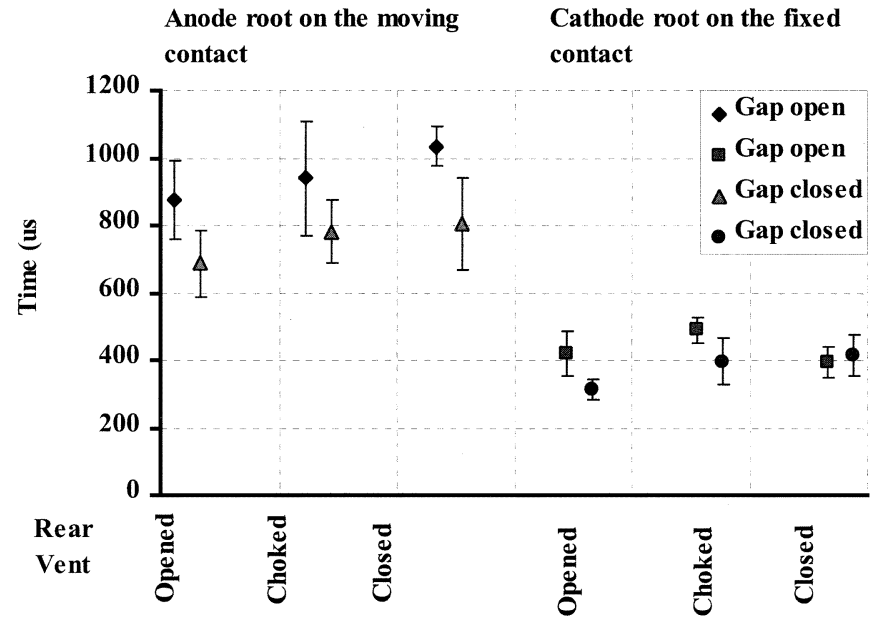

Fig. 8. Influence of gap behind the moving contact on anode root on moving contact and cathode root on fixed contact as arc chamber venting opened, choked, closed condition, $\mathrm{Ag} / \mathrm{C}$ step, contact opening velocity $10 \mathrm{~m} / \mathrm{s}$, ceramic arc chamber, the cathode and anode root contact time are presented with \pm 1 standard deviation.

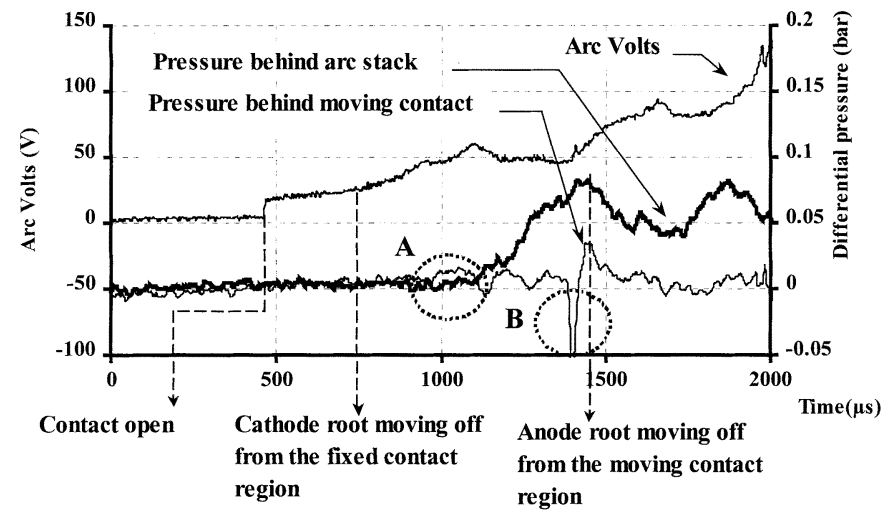

Fig. 9. Pressure behind the moving contact and behind the arc stack at contact opening velocity $10 \mathrm{~m} / \mathrm{s}$, Gap open, $\mathrm{Cu}$ punch, ceramic arc chamber, anode on moving contact, and cathode on fixed contact.

\section{B. Experiment B: The Influence of Gas Flow Around the Moving Contact}

The importance of the gas flow around the moving contact has been observed in [1]. In this paper, the influence on arc commutation is quantified. The conditions used are a ceramic arc chamber operating with a contact velocity of $10 \mathrm{~m} / \mathrm{s}$. The open gap behind the moving contact can be observed in Figs. 2 and 10. To close the gap and to prevent gas flow a ceramic stop is used. Fig. 8 shows the anode and cathode root times with the condition of the vent behind the moving contact. The anode root time on the moving contact with the gap open is longer than with the gap closed. It moves from the contact region $17-24 \%$ faster with the gap closed. The results indicate that the gap behind the moving contact has an important influence on the anode root motion on the moving contact [1]. The cathode root contact times are lower than the anode, due to different measurement criteria on the fixed contact. The cathode contact time shows no significant correlation with the gap behind the moving contact. The effect of the venting behind the splitter plates is shown, and has been reported previously [1]. In the following studies the vent is in 


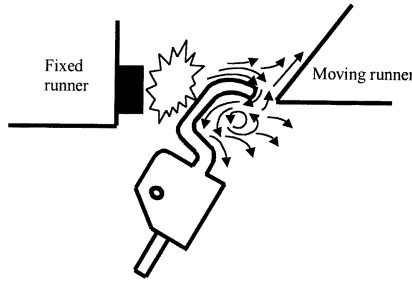

(a)

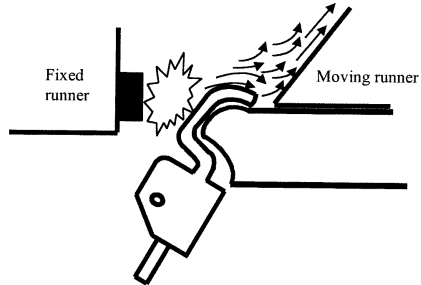

(b)
Fig. 10. Gas flow around the moving contact.

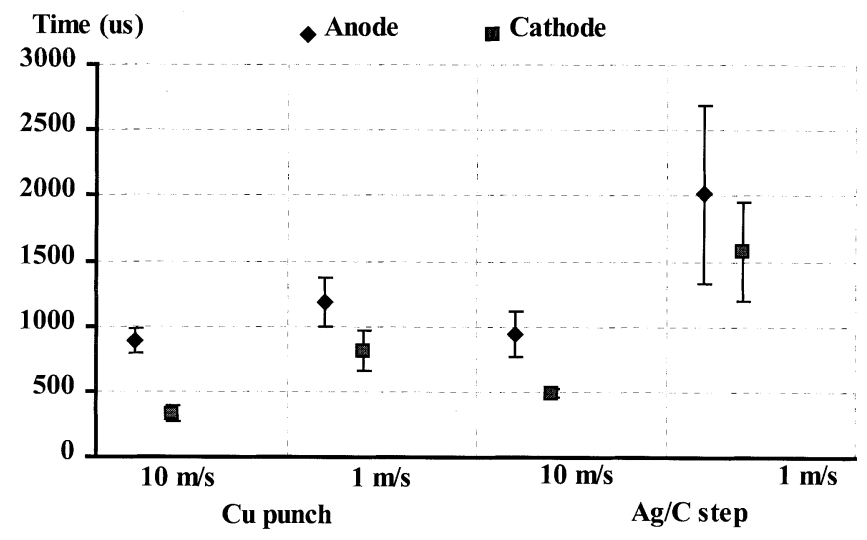

Fig. 11. Anode and cathode root contact times on the contact opening velocity $1 \mathrm{~m} / \mathrm{s}$ and $10 \mathrm{~m} / \mathrm{s}$, Cu punch and $\mathrm{Ag} / \mathrm{C}$ step contact material and choked arc chamber venting, anode on moving contact and cathode on fixed contact.

the choked configuration, as this closely matches a commercial configuration.

For the condition with the main vent choked and the gap behind the moving contact open Fig. 9 shows the changes in the pressure behind the moving contact and behind the arc stack with the arc voltage. At A in Fig. 9 the pressure behind the contact starts to rise before the pressure behind the arc stack. It is thought that the gas flow moves around the edge of the moving contact and out from the arc chamber, forming strong circulating flows behind the moving contact as shown in Fig. 10. When the gap is closed, all of the metallic vapor and arc energy transfers directly to the arc runner. Additionally, the gas flow toward the arc stack is increased. This promotes fast arc transfer from the moving contact. When the arc roots move off from the contact region, the pressure behind the arc stack is higher than the pressure behind moving contact. The drop in the pressure behind the moving contact (at B) is produced as the anode root moves away from the contact region.

\section{Experiment C: Contact Materials, Arc Chamber Material and Reduced Contact Velocity}

Decreasing the contact opening velocity leads to an increase in the delay both on the anode and cathode root contact time as shown in Fig. 7. The condition of the choked arc chamber with the gap open shown in Fig. 8 is repeated here as the starting point for the investigation, in Fig. 11. For the same conditions

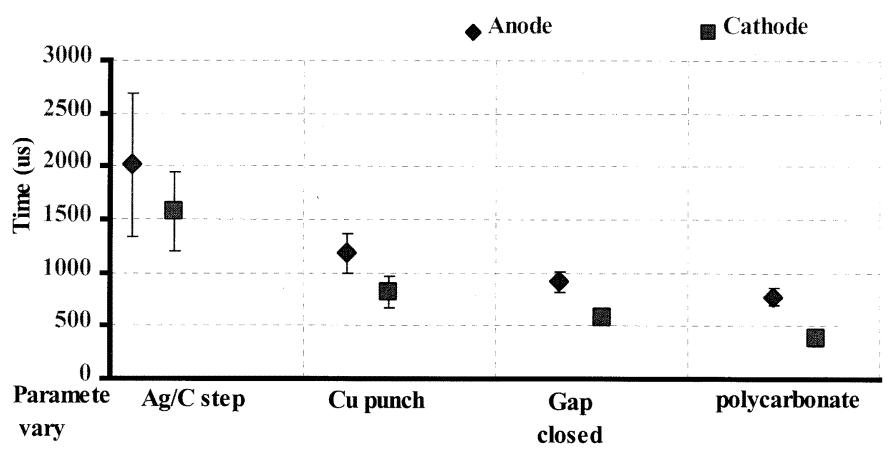

Fig. 12. Development of the arc control at the low contact opening velocity $1 \mathrm{~m} / \mathrm{s}$, choked vent arc chamber, anode on the moving contact and cathode on the fixed contact.

with a reduced contact velocity the anode and cathode root contact times are more than doubled to $2000 \mu \mathrm{s}$ and $1500 \mu \mathrm{s}$, respectively. This was also the case in the Experiment $\mathrm{A}$ in Figs. 5 and 7 for a different chamber material. Fig. 11 also shows the influence of the $\mathrm{Ag} / \mathrm{C}$ contact material (with a step) on the delay. Removing the $\mathrm{Ag} / \mathrm{C}$ reduces the contact times. Fig. 12 shows a further sequence of development where the contact times for both the anode and the cathode are sequentially reduced. Firstly by removing the $\mathrm{Ag} / \mathrm{C}$ then by closing the gap behind the moving contact and finally by adding the polycrabonate wall material. The final contact times are then comparable with the basic ceramic chamber using $10 \mathrm{~m} / \mathrm{s}$ and a $\mathrm{Ag} / \mathrm{C}$ tip in Fig. 11. This figure demonstrates that the arc chamber can be designed to operate at $1 \mathrm{~m} / \mathrm{s}$. It is important to note that in most commercial devices the gap behind the moving contact is open.

In Fig. 13, results are presented for an arc chamber configuration which is representative of a commercial application where the chamber is manufactured from a polycarbonate with a gap behind the moving contact. These results are shown on the left for the high contact velocity and in the middle with the low velocity. By closing the gap behind the moving contact there is a significant improvement in performance for the low velocity condition. This work suggests that gas dynamics around the contact tip is essential to the performance of the circuit breaker.

\section{Experiment D: Gas Composition}

To investigate further the influence of the polycarbonate on the gas flow a spectrographic study has been undertaken. In this case the results show the spectra from the arc for the whole period the arc is in the contact region. Figs. 14 and 15 show spectra in the contact region of ceramic and polycarbonate arc chamber material with a $10 \mathrm{~m} / \mathrm{s}$ opening velocity. The possible element species corresponding to these spectrum lines are presented in Table II. The spectrum line of Ag is apparent in both Fig's at the wavelength 521 and 546 at a different intensity level indicating a different temperature over the integration period. These results correspond with previous observations [12], [13]. These results show the potential for using the spectrographic test to determine material composition in the arc during the short circuit event. 


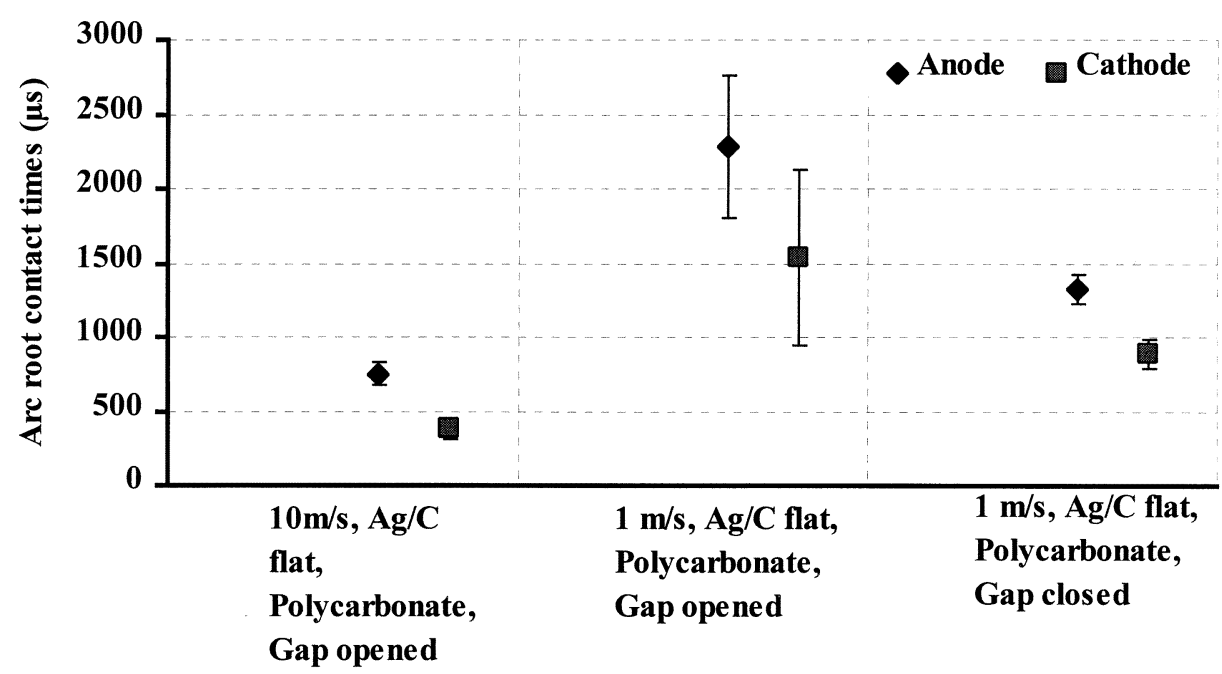

Fig. 13. Influence of the gap behind the moving contact at low velocity with a polycarbonate chamber with $\mathrm{Ag} / \mathrm{C}$ material without a step.

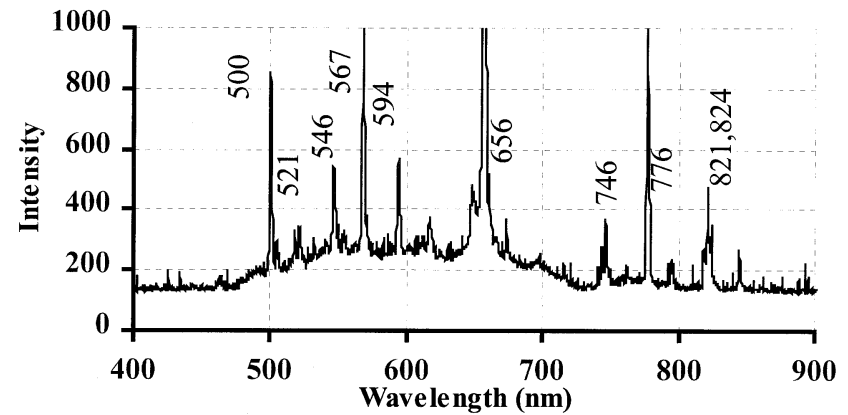

Fig. 14. Spectrum line in ceramic arc chamber, $\mathrm{Ag} / \mathrm{C}$ flat contact material, Contact velocity $10 \mathrm{~m} / \mathrm{s}$, Choked arc chamber venting condition, anode on moving contact and cathode on fixed contact.

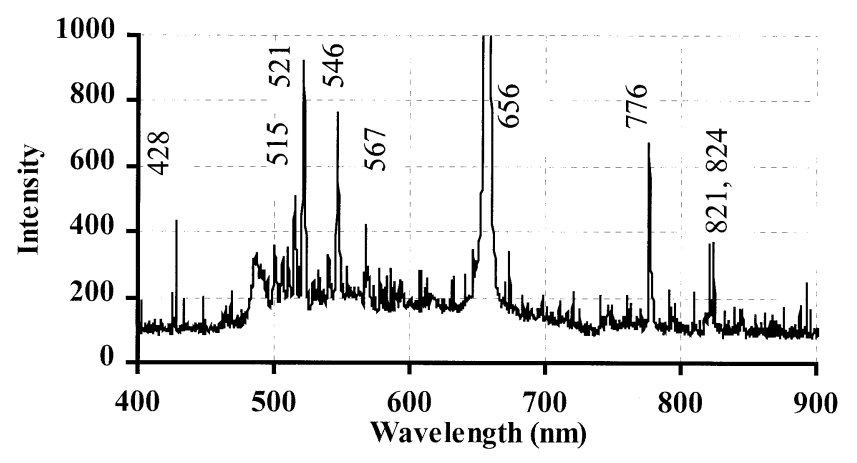

Fig. 15. Spectrum line in polycarbonate arc chamber, $\mathrm{Ag} / \mathrm{C}$ flat contact material, contact velocity $10 \mathrm{~m} / \mathrm{s}$, choked arc chamber venting condition, anode on moving contact and cathode on fixed contact.

\section{CONCLUSION}

New results from pressure and spectral measurement are combined with optical data of arc root motion. These data give valuable new insights into the arc root motion from the contact for a range of arc chamber materials, venting conditions and moving contact velocities. These results are essential in the development of a computer based simulation of the arc motion in the arc chamber, with an opening contact.

Low contact opening velocity results in higher pressures in the contact region. This correlates with long arc root contact
TABLE II

Possible Element SPeCIES IN THE SPECTRUM LiNES

\begin{tabular}{l|l}
\hline $\begin{array}{l}\text { Wavelength } \\
(\mathrm{nm})\end{array}$ & Possible element species \\
\hline 428 & N III, O II \\
\hline 500 & O II, O IV, Ti VIII, Al IV, N \\
\hline 515 & C V, O II, O IV, N V \\
\hline 521 & Ag I \\
\hline 546 & Ag I \\
\hline 567 & C III, O V \\
\hline 594 & O IV, C II, Al IV, N IV \\
\hline 656,657 & N II, H, O II \\
\hline 746 & C V, Al IV, N II \\
\hline 776,777 & O I, N II, C III, Cu II \\
\hline 821,824 & O III, O IV, O VIII, N III, N \\
& IV \\
\hline
\end{tabular}

times on both copper and $\mathrm{Ag} / \mathrm{C}$ contacts. Closing the gap behind the opening contact will benefit the low velocity operation of a current limiting circuit breaker.

\section{REFERENCES}

[1] J. W. McBride, K. Pechrach, and P. M. Weaver, "Arc root commutation from moving contacts in low voltage devices," IEEE Trans. Comp. Packag. Technol., vol. 24, pp. 331-336, Sept. 2001.

[2] J. W. McBride and P. M. Weaver, "Review of arcing phenomena in low voltage current limiting circuit breakers," Proc. Inst. Elect. Eng., vol. 148, pp. 1-7, Jan. 2001.

[3] J. W. McBride and P. A. Jeffery, "Anode and cathode arc root movement during contact opening at high current," IEEE Trans. Comp., Packag., Manufact. Technol. A, vol. 22, pp. 38-46, Mar. 1999.

[4] J. W. McBride, P. M. Weaver, and P. Jeffery, "Arc root mobility during contact opening at high current," IEEE Trans. Comp., Packag., Manufact. Technol. A, vol. 21, pp. 61-67, Mar. 1998. 
[5] P. A. Jeffery, J. W. McBride, J. Swingler, and P. M. Weaver, "An investigation into arc contact phenomena and current limiting performance of miniature circuit breakers using the taguchi design of Experiments," in Proc. 19th Int. Conf. Electrical Contacts, Germany, Sept. 14-17, 1998, p. 473.

[6] M. Lindmayer and M. Paulke, "Arc motion and pressure formation in low voltage switchgear," IEEE Trans. Comp., Packag., Manufact. Technol. A, vol. 21, pp. 33-39, Mar. 1998.

[7] J. J. Shea, "The influence of arc chamber wall material on arc gap dielectric recovery voltage," IEEE Trans. Comp. Packag. Technol., vol. 24, pp. 342-348, Sept. 2001.

[8] P. M. Weaver and J. W. McBride, "Magnetic and gas dynamic effects on arc motion in miniature circuit breakers," IEEE Trans. Comp., Packag., Manufact. Technol. A, vol. 17, pp. 39-45, Mar. 1994.

[9] M. Abbaoui and B. Cheminat, "Determination of the characteristics of an electric arc plasma contaminated by vapors from insulators," IEEE Trans. Plasma Sci., vol. 19, pp. 1-8, Feb. 1991

[10] C. Fievet, P. Petit, M. Y. Perin, P. chevrier, and G. Bernard, "Residual conduction in low voltage circuit breaker," in Proc. 11th Int. Conf. Gas Discharges Applicat., Tokyo, Japan, Sept. 11-15, 1995, pp. 26-28.

[11] PC2000 PC plug-in spectrometer, Ocean Optics, Inc. (2001). [Online]. Available: www.oceanoptics.com/products/pc2000.asp

[12] K. Sato, T. Sato, and T. Takagi, "Development of a high speed time- - Resolved spectroscope and its application to analysis of time varying optical spectra," IEEE Trans. Instrum. Meas., vol. IM-36, pp. 1045-1049, Dec. 1987.

[13] K. Yoshida and A. Takahashi, "Spectroscopic measurement of Ag breaks arc," Proc. Int. Conf. Elect. Contact, pp. 51-58, 1994.

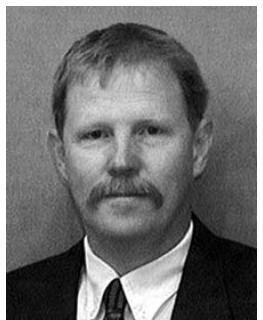

John W. McBride received the M.S. degree in aeronautical engineering from the University of Southampton, Southampton, U.K., in 1978, and the $\mathrm{Ph} . \mathrm{D}$. degree in electrical contact phenomena from Plymouth University, Plymouth, U.K., in 1986.

From 1985 to 1987, he lectured in the Mechanical Engineering Department, Plymouth University, and since 1987, has been a Lecturer, Senior Lecturer, and a Reader in instrumentation and measurement in the School of Engineering Science, Electrical Engineering Department, University of Southampton. Since 2001, he has been Professor of electromechanical engineering in the School of Engineering Science. He is Chair of the Electromechanical Research Group, and Deputy Head of the School. His main research interests include electrical contacts, metrology, and instrumentation.

Dr. McBride is an Associate Editor of the IEEE TRANSACTIONS ON Components and PaCKAging TeChNologies, a Chartered Engineer, and Chair of the Electro-Mechanical Research Group, and Vice Chair of IEE professional group S3 Electron Physics, Plasmas, and applications. He is a member of the Organizing Committee, IEEE Holm Conference on Electrical Contacts.

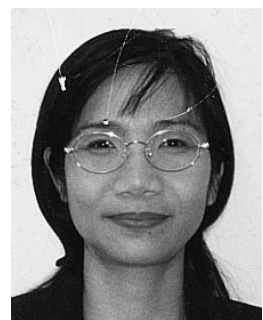

Kesorn Pechrach (M'97) received the B.Eng. degree in electrical engineering from Khonkaen University, Thailand, in 1992, the M.Eng. degree in energy technology from King Mongkut's University of Technology, Thonburi, Thailand, in 1997, and is currently pursuing the Ph.D. degree in the Electromechanical Research Group, University of Southampton, Southampton, U.K.

She has worked for consulting engineer companies as a Lead Electrical Engineer since 1992. Her responsibilities included the design and engineer supervision of electrical facilities for industrial plants, commercial building, roadways, refineries, and HV substations.

Ms. Pechrach is a Chartered Electrical Engineer of the Engineering Institute of Thailand.

Paul M. Weaver received the B.A. degree (with honors) in natural science from the University of Cambridge, Cambridge, U.K. and the Ph.D. degree in aeronautical engineering from the University of Southampton, Southampton, U.K.

$\mathrm{He}$ is Research Manager at PBT, Ltd., Harlow, U.K. He has been working in industry since 1993 in research and development of circuit breakers and related switching systems and has published widely in this field. Prior to this, he was a Research Fellow at Southampton University researching short circuit arc phenomena. His research interests include switching arc phenomena, smart materials actuation, and sensor technologies.

Dr. Weaver is a member of the IEE. 